\title{
Synthesis of $\boldsymbol{N}$-acetylneuraminic acid and of CMP- $\boldsymbol{N}$-acetylneuraminic acid in the rat liver cell
}

\author{
Wijnholt FERWERDA, Corrie M. BLOK and Johanna VAN RINSUM \\ Department of Medical Chemistry, Vrije Universiteit, Van der Boechorststraat 7, \\ NL-1007 MC Amsterdam, The Netherlands
}

(Received 9 May 1983/Accepted 19 July 1983)

\begin{abstract}
Adult male rats, under starving and normal conditions, were injected intravenously with $\mathrm{N}$-acetyl $\left[{ }^{3} \mathrm{H}\right]$ mannosamine and after various time intervals the specific radioactivities of free $N$-acetylneuraminic acid (NeuAc) and CMP- $N$-acetylneuraminic acid were determined in the liver. The specific radioactivity of free NeuAc was high even within $20 \mathrm{~s}$ after injection; the maximum was reached between 7 and $10 \mathrm{~min}$. The specific radioactivity of CMP-NeuAc showed a lag phase of approx. $1 \mathrm{~min}$. Thereafter it increased quickly and rose above the specific radioactivity of free NeuAc, reaching a maximum about $20 \mathrm{~min}$ after injection. These results point to a channelling of the newly synthesized NeuAc molecules into a special compartment, from which they are preferentially used by the enzyme CMP-sialic acid synthetase. It is suggested that the cytosolic enzyme $N$-acetylneuraminic acid 9-phosphate phosphatase is working in concert with the nuclear localized enzyme CMP- $N$-acetylneuraminic acid synthetase. Incorporation of radioactive sialic acid into sialoglycoproteins in liver occurred 2 min after injection, and after $10 \mathrm{~min}$ bound radioactivity began to appear in the circulation, indicating a transport time of $8 \mathrm{~min}$ of sialoglycoproteins from the point of attachment of sialic acid to the point of excretion.
\end{abstract}

Sialic acid plays an important role in biological phenomena, being the negatively charged terminal sugar of many glycoproteins. Sialic acid is thought to be synthesized in its non-modified form, NeuAc, by a series of enzymes in the cytosol (for reviews, see Warren, 1972; McGuire, 1976). Recently we were able to confirm the cytosolic localization of some precursor-forming enzymes (Van Rinsum et al., 1983). The enzyme that activates NeuAc, CMPNeuAc synthetase, is localized in the nucleus (Kean, 1970; Gielen et al., 1970, 1971; Van den Eijnden, 1973; Van Dijk et al., 1973; Coates et al., 1980), whereas the transfer of NeuAc to various glycoprotein and glycolipid acceptors takes place in the Golgi apparatus (for reviews, see Schachter, 1974; Schachter \& Roseman, 1980). Modifying reactions, such as $O$-acylation and $N$-hydroxylation, can occur in the Golgi region and perhaps in the cytosol (Corfield et al., 1976; Buscher et al., 1977). In

Abbreviations used: NeuAc, $N$-acetylneuraminic acid; ManNAc, $\quad N$-acetyl-D-mannosamine; h.p.l.c., highpressure liquid chromatography. addition, a CMP-NeuAc hydrolase exists, which is predominantly found in the plasma membrane (Kean \& Bighouse, 1974; Van Dijk et al., 1976, 1977). The significance of this distribution at a topographical level is unknown, but it might indicate a high degree of regulation of sialic acid metabolism. Assuming that CMP-NeuAc synthetase is functionally active in the nucleus (Coates et al., 1980), the question arises as to how this synthetase is interrelated with the cytosolic NeuAc-forming enzymes. Studying the metabolism of sialic acid in rat brain, after intracranial injection of the specific precursor $N$ - $\left[{ }^{3} \mathrm{H}\right]$ acetyl-D-mannosamine, we observed a higher specific radioactivity of CMP-NeuAc than of free NeuAc, in the first few hours after the pulse (Ferwerda et al., 1981a). This result points to a channelling of the newly synthesized NeuAc molecules to a special compartment, where they will be used directly by CMP-NeuAc synthetase. We have now extended our studies to rat liver to investigate whether this phenomenon is general or specific to the brain. In addition, we have measured the incorporation of radioactivity into bound NeuAc 
and the time between incorporation and excretion. Part of this work has been presented previously (Ferwerda et al., 1981b).

\section{Materials and methods}

$N$-Acetyl[ $\left.4-{ }^{14} \mathrm{C}\right]$ neuraminic acid (sp. radioactivity $57 \mathrm{Ci} / \mathrm{mol}), \quad \mathrm{CMP}-\mathrm{N}$-acetyl $\left[4-{ }^{14} \mathrm{C}\right]$ neuraminic acid (sp. radioactivity $1-2 \mathrm{Ci} / \mathrm{mol}$ ) and $N$-acetyl-D- $\left[{ }^{3} \mathrm{H}\right]-$ mannosamine [G- ${ }^{3} \mathrm{H}$; sp. radioactivity $2807 \mathrm{Ci} / \mathrm{mol}$; or $6(\mathrm{n})-{ }^{3} \mathrm{H}$, sp. radioactivity $19000 \mathrm{Ci} / \mathrm{mol}$ ] were obtained from New England Nuclear, Boston, MA, U.S.A. (During our experiments the delivery of the ManNAc with lower specific radioactivity was stopped.) NeuAc was purchased from Koch-Light Laboratories, Colnbrook, Bucks., U.K.; 2,3-dehydro2-deoxy- $\mathrm{N}$-acetylneuraminic acid was from Boehringer-Mannheim G.m.b.H., Mannheim, Germany, and Dowex AG1 (X8) was from Bio-Rad, Richmond, CA, U.S.A.

All other chemicals were of analytical grade.

\section{Animals}

Male Wistar rats of 2-3 months old (weight 190$220 \mathrm{~g}$ ) were used. The rearing conditions were: light from $08: 00 \mathrm{~h}$ to $20: 00 \mathrm{~h}$, temperature $18-20^{\circ} \mathrm{C}$, food from 7:00h to $9: 00 \mathrm{~h}$ and water ad libitum. The rats easily adapted to this schedule, although their growth was somewhat retarded. On the day of injection no food was given. These rats are referred to as starved rats. Rats fed ad libitum (weight 220$240 \mathrm{~g}$ ) are designated as normal rats.

The rats were injected intravenously between $09: 00 \mathrm{~h}$ and $11: 00 \mathrm{~h}$ with $0.5 \mathrm{ml}$ of phosphatebuffered saline, $\mathrm{pH} 7.4$, containing $100 \mu \mathrm{Ci}$ of $\left[{ }^{3} \mathrm{H}\right]$ ManNAc. They were killed by immersing the whole animal in liquid $\mathrm{N}_{2}$, whereafter the bodies were stored at $-40^{\circ} \mathrm{C}$. The livers and sometimes the heart and large blood vessels were removed in a frozen state. Therefore the frozen animal was cut into pieces with the aid of a guillotine and the organs were rapidly dissected out in the cold to prevent thawing, and stored in liquid $\mathrm{N}_{2}$ until use. To check the effect of the killing procedure on the results, some animals were killed by decapitation, the livers were rapidly removed and stored in liquid $\mathrm{N}_{2}$.

\section{Isolation and purification of free NeuAc and of CMP-NeuAc}

The procedure used was a modification of the method described previously (Ferwerda et al., $1981 a$ ). Briefly, the frozen livers were weighed and, avoiding thawing, immediately homogenized in $9 \mathrm{vol}$. of cold $75 \%(\mathrm{v} / \mathrm{v})$ ethanol, sonicated for $1 \mathrm{~min}$ and centrifuged at $105000 \mathrm{~g}$ for $1 \mathrm{~h}$, at $0-4^{\circ} \mathrm{C}$ in an MSE-50 centrifuge $(8 \times 50 \mathrm{ml}$ angle rotor $)$. After evaporation of the ethanol the extracted material was dialysed at $0^{\circ} \mathrm{C}$ against $250 \mathrm{ml}$ of $5 \mathrm{~mm}$-Teb (triethylammonium bicarbonate) buffer, $\mathrm{pH} 7.8$, containing $1 \mathrm{ml}$ of toluene/litre to prevent bacterial growth. The diffusate was evaporated, the material solubilized in a few millilitres of the same buffer and transferred on to a Dowex AG1 (X8; $\mathrm{HCO}_{3}{ }^{-}$form; $100-200 \mathrm{mesh})$ column $(100 \mathrm{~cm} \times 0.5 \mathrm{~cm})$. Elution was achieved with a linear concentration gradient of $0.005-0.25 \mathrm{M}$-Teb buffer. The radioactivity of the fractions was determined and the various peaks were pooled and concentrated by evaporation. The positions of the different metabolites on the column were checked with radioactive standards. Fractions containing free NeuAc were pooled, the content of $\mathrm{NeuAc}$ and the radioactivity were determined in triplicate and the specific radioactivity was calculated. This material still contained some radioactive impurities. To correct for this, h.p.l.c. was performed on an analytical scale by the method of Bergh et al. (1981). Normally, $70-80 \%$ of the radioactivity appeared to coincide with NeuAc and the specific radioactivity was corrected accordingly. With exogenous $\left[{ }^{14} \mathrm{C}\right] \mathrm{NeuAc}$, it was shown that the impurities were formed in part during the purification procedure, probably during evaporation in Teb buffer, which can lead to a $\mathrm{pH}$ of approx. 9.

The CMP-NeuAc-containing material was hydrolysed under very mild conditions $\left(1 \mathrm{~h}\right.$ at $80^{\circ} \mathrm{C}$, in bidistilled water acidified with formic acid to pH4-5) and rechromatographed on a small Dowex AG1 (X8; $\mathrm{HCO}_{3}^{-}$form; $100-200$ mesh) column $(5 \mathrm{~cm} \times 0.5 \mathrm{~cm})$, eluted stepwise with $\mathrm{Teb}$ buffer. Fractions containing NeuAc, eluted at a concentration of $40 \mathrm{~mm}$-Teb buffer, were pooled, evaporated and the radioactivity and the content of NeuAc were determined in triplicate. The specific radioactivity could be calculated after analysis with h.p.l.c. as described above; $80-90 \%$ of the radioactivity coincided with NeuAc. Some 2-deoxy-2,3dehydro- $N$-acetylneuraminic acid was always found, which is formed during evaporation of CMP-NeuAc under mild alkaline conditions (Beau et al., 1978).

The concentrations of free NeuAc and of CMPNeuAc in vivo were measured with the isotopedilution technique using ${ }^{14} \mathrm{C}$-labelled standards. The purification procedure was the same as described above. To determine whether hydrolysis of bound NeuAc easily occurred some measurements were performed after homogenization of the liver in distilled water.

\section{Isolation and purification of bound NeuAc}

A suitable portion was taken from the liver pellets, obtained after centrifugation of the homogenates (see above), and washed by dispersion and centrifugation in $70 \%$ ethanol. The NeuAc was released using $0.05 \mathrm{M}-\mathrm{H}_{2} \mathrm{SO}_{4}$ and purified as described previously (Ferwerda et al., 1981a). Small Dowex AG1 (X8; $\mathrm{HCO}_{3}^{-}$form; 100-200 mesh) columns 
$(5 \mathrm{~cm} \times 0.5 \mathrm{~cm})$ were used for purification and were eluted stepwise with Teb buffer.

Serum was obtained from the heart and large blood vessels after thawing, clotting and centrifugation. Some haemolysis could not be avoided. The serum was extensively dialysed at $0^{\circ} \mathrm{C}$ against distilled water to eliminate low-molecular-weight radioactive compounds. Subsequently, the serum was hydrolysed and the NeuAc was purified as described above. The specific radioactivity of the purified NeuAc was calculated after determination of the content of NeuAc and of the radioactivity.

\section{Analytical techniques}

Teb-stock buffer was prepared by bubbling $\mathrm{CO}_{2}$ into a $1.25 \mathrm{M}$ solution of triethylamine in a closed vessel under constant stirring at $4^{\circ} \mathrm{C}$ until the $\mathrm{pH}$ was 7.8. The various concentrations were prepared by dilution. Sialic acid was measured by the thiobarbituric acid method (Warren, 1959). Radioactivity was counted in a Berthold liquid-scintillation counter (model BF 8000) equipped with an automatic external standard for calculation of d.p.m.

\section{Results and discussion}

The metabolism of rats fed only $2 \mathrm{~h}$ a day became typical for starving conditions. The total body weight remained almost the same, no fat deposits were formed and the liver weight (4-5g) was approximately half that of normal rats. With such rats the biological variation was reduced, resulting in a better reproducibility. However, to exclude the possibility that starvation introduced misleading results we also investigated a series of rats fed ad libitum.

The quantity of $\left[{ }^{3} \mathrm{H}\right]$ ManNAc injected was $36 \mathrm{nmol}$ (sp. radioactivity $2807 \mathrm{Ci} / \mathrm{mol}$ ) or $5.3 \mathrm{nmol}$ (sp. radioactivity $19000 \mathrm{Ci} / \mathrm{mol}$ ). The livers of starved rats as well as of normal rats absorbed very little of the injected ManNAc. After correction for the radioactivity present in blood it could be calculated that from the 36 or $5.3 \mathrm{nmol}$ injected, between 1 and $2 \%$ was absorbed by the liver. This corresponds to maximally 0.7 and $0.1 \mathrm{nmol}$ respectively of ManNAc, a negligible quantity compared with the total amount of metabolites under investigation (Table 1). It appeared that injection of $5.3 \mathrm{nmol}$ with the higher specific activity resulted in somewhat higher specific radioactivity of the metabolites than injection of $36 \mathrm{nmol}$ with the lower specific radioactivity. Most of the injected radioactivity was rapidly cleared from the circulation by the kidneys. After $10 \mathrm{~min}$ over $50 \%$ had already been excreted. Harms \& Reutter (1974) reported an absorption of approx. $3 \%$ by the liver of normal male Buffalo rats independent of the injected quantity. However, they did not correct for the blood content of liver.
The values shown in Table 1 were obtained after killing the animals in liquid $\mathrm{N}_{2}$ and homogenization in ethanol. It appeared that homogenization in water resulted in 2-fold higher values for free NeuAc, whereas the values found for CMP-NeuAc remained the same. Probably some bound NeuAc can be split off in water by the enzyme sialidase, even in the cold, as has been reported for rat brain (Irwin et al., 1973). Killing by the liquid- $\mathrm{N}_{2}$ method or by decapitation resulted in the same values. We decided to use the liquid- $\mathrm{N}_{2}$ method to stop the metabolic processes as abruptly as possible. A few seconds after immersing the animal in liquid $\mathrm{N}_{2}$ the liver will be frozen. So time corrections can be avoided, perhaps with the exception of periods shorter than $1 \mathrm{~min}$.

The reliability of the procedure is very important in view of the results described below. The effect of bound NeuAc split off during the procedure, especially, can introduce misleading results. No indications exist that in our procedure such a hydrolysis occurred. In addition, frozen liver freezedried on a cold plate and homogenized as dry powder in cold ethanol gave fully comparable results (results not shown).

The specific radioactivities of free NeuAc and of CMP-NeuAc were determined at various time intervals. A few minutes after injection the specific radioactivity of free NeuAc was high. The maximum was reached after $7-10 \mathrm{~min}$, and then it declined slowly. During the first few minutes the specific radioactivity of CMP-NeuAc was low, but it increased quickly and rose above the specific radioactivity of free NeuAc, remaining higher for more than $2 \mathrm{~h}$. The maximum was reached between 15 and $20 \mathrm{~min}$. The specific radioactivities found for normal rats were lower than those of starved rats, but the profiles of the curves were similar (Fig. 1). As we used the ManNAc batch with low specific radioactivity $(2807 \mathrm{Ci} / \mathrm{mol})$ for starved rats and the batch with high specific radioactivity $(19000 \mathrm{Ci} / \mathrm{mol})$ for normal rats the observed differences between starved and normal rats should be more pronounced. From our experiments it became clear that the livers of starved rats have a greater absorption capacity for ManNAc than the livers of normal rats. The livers

Table 1. Concentration of free NeuAc and of CMPNeuAc in rat liver

Values are expressed as means \pm S.E.M. The numbers of experiments are given in parentheses.

$\begin{array}{lcc}\overbrace{\text { Starved rats }}^{\text {Concentration (nmol/g wet wt.) }} & \text { Normal rats } \\ \text { Free NeuAc } & 80 \pm 6(6) & 94 \pm 9(7) \\ \text { CMP-NeuAc } & 30 \pm 1(8) & 34 \pm 2(4)\end{array}$


of starved rats absorbed even more than twice as much per $\mathrm{g}$ wet wt. A greater absorption capacity by hepatic cells during starving conditions was also observed by Summerfield (1982) for the uptake of agalacto-orosomucoid.

On the basis of our observations the conclusion can be drawn that in liver, as in brain, newly synthesized NeuAc molecules are channelled to CMP-NeuAc synthetase. To determine whether the newly synthesized NeuAc molecules are directly transferred to the synthetase or are directed into a special compartment (the substrate pool of the synthetase), we measured the specific radioactivities of NeuAc and of CMP-NeuAc in a series of starved rats very shortly after injection. If a special compartment exists the specific radioactivity of CMP-NeuAc should show a lag phase relative to the specific radioactivity of NeuAc; the duration of the lag phase gives an indication of the size of the substrate pool. The specific radioactivity of free NeuAc was high from the first test point $(20 \mathrm{~s})$, and thereafter it increased further. The specific radioactivity of CMP-NeuAc showed a lag phase of $40-60 \mathrm{~s}$, after which time it increased quickly (Fig. 1, inset). This result points to the existence of a special pool of newly synthesized NeuAc molecules. A half-life of CMP-NeuAc shorter than 20 min can be calculated from the decrease in specific radioactivity between 30 and $50 \mathrm{~min}$ (Fig. 1) in the liver of starved rats. An exact determination is not possible because incorporation of radioactivity into
CMP-NeuAc still continues during this time. From this half-life and the pool size of CMP-NeuAc (Table 1) it can be calculated that the synthesis rate of CMP-NeuAc is greater than $1.0 \mathrm{nmol} / \mathrm{min}$ per $\mathrm{g}$ wet wt. A lag phase of $1 \mathrm{~min}$ points to a pool of NeuAc for synthesis of more than $1.0 \mathrm{nmol} / \mathrm{g}$ wet wt.

The difference in lag phase between CMP-NeuAc and NeuAc should be used for an exact calculation, but for NeuAc no lag phase could be determined. In addition, after $1 \mathrm{~min}$ the incorporation of radioactivity into CMP-NeuAc started, but the pool for synthesis may only be partly renewed. However, it is clear that the pool for synthesis is small, maximally a few percent of the total amount of free NeuAc in the liver.

As mentioned in the introduction, CMP-NeuAc synthetase is localized in the nucleus. Experiments with nucleus-free cells (Coates et al., 1980) give support to the idea that CMP-NeuAc synthetase is also functionally active in the nucleus. The channelling of newly synthesized NeuAc molecules can be explained by the assumption that the last enzyme in NeuAc biosynthesis, NeuAc 9-phosphatase, delivers its product into the special pool, in this case the nucleus. The subcellular localization of the NeuAc 9-phosphatase has never been determined. No indications exist that this enzyme is nuclear-bound; on the contrary the results of the investigations point to a cytosolic localization (Warren \& Felsenfeld, 1962; Jourdian et al., 1964; Watson et al., 1966). However, cytosol-localized

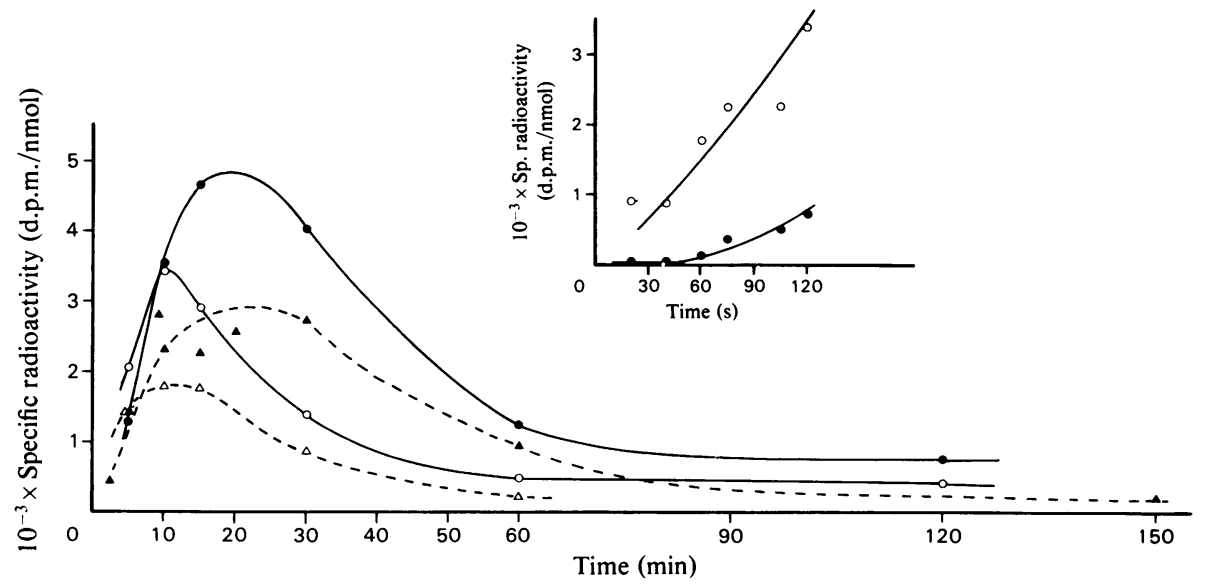

Fig. 1. Time course of the specific radioactivities of CMP-NeuAc and of free NeuAc in rat liver after a single injection of $100 \mu \mathrm{Ci}$ of $\left[{ }^{3} \mathrm{H}\right] \mathrm{ManNAC}$

Rats were killed at various time intervals after injection by immersing the whole animal in liquid $\mathrm{N}_{2}$. The livers were removed in a frozen state and CMP-NeuAc and free NeuAc were isolated and purified as described in the Materials and methods section. Starved rats: 0, CMP-NeuAc; O, free NeuAc; sp. radioactivity of the injected $\left[{ }^{3} \mathrm{H}\right]$ ManNAc was $2807 \mathrm{Ci} / \mathrm{mol}$ (inset: sp. radioactivity $19000 \mathrm{Ci} / \mathrm{mol}$ ). Normal rats: $\Delta$, CMP-NeuAc; $\Delta$, free NeuAc; sp. radioactivity of the injected $\left[{ }^{3} \mathrm{H}\right] \mathrm{ManNAc}$ was $19000 \mathrm{Ci} / \mathrm{mol}$. The indicated times in the main Figure and in the inset are the periods between injection and immersion in liquid $\mathbf{N}_{2}$. 
enzymes need not be freely diffusible, but are often functionally ordered within the cell. Interaction with structural components can occur, sometimes resulting in modified catalytic activities (for review, see Masters, 1978). In the case of NeuAc-synthesis it might be that NeuAc 9-phosphatase is adsorbed on the nuclear membrane in its active state, resulting in the delivery of newly synthesized NeuAc into the special pool. We realize that this hypothesis needs experimental support. One important objective is to prove that CMP-NeuAc synthetase is really functionally active in the nucleus and does not exert its action elsewhere. It is noteworthy that in liver a relatively high concentration of $300-400 \mathrm{nmol}$ of UDP-GlcNAc/g wet wt. exists (Molnar et al., 1964; Bates et al., 1966; Harms et al., 1973), whereas the concentrations of ManNAc, ManNAc 6-phosphate and NeuAc 9-phosphate are low or below the detectable level (Voisey \& Winterburn, 1982; W. Ferwerda, C. M. Blok \& J. Van Rinsum, unpublished work). This might indicate that a highly ordered system exists of the enzymes UDP-GlcNAc 2-epimerase, ManNAc kinase, NeuAc 9-phosphate synthetase and NeuAc 9-phosphatase working in concert with UDP-GlcNAc as starting substrate and resulting in the synthesis of NeuAc.

The activated sugar, CMP-NeuAc, has to be transported to the Golgi vesicles. This can occur through the lumen of the contiguous membrane system of the rough and smooth endoplasmic reticulum, as has been suggested by Hanover \&

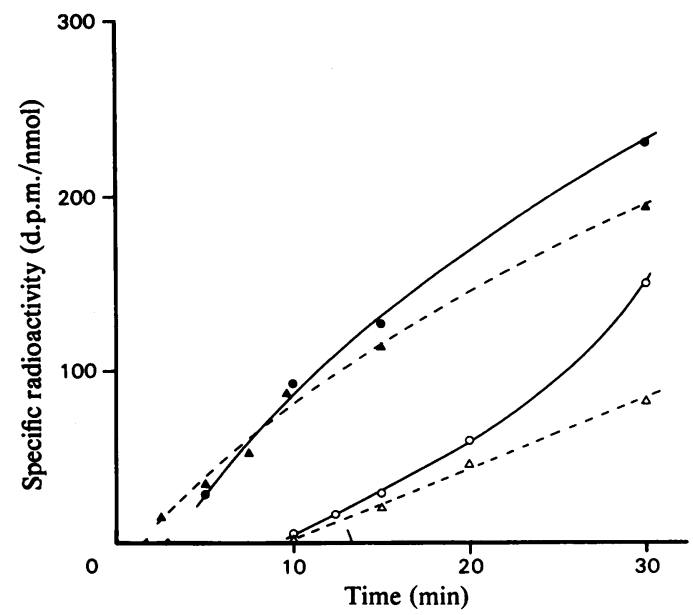

Fig. 2. Time course of the specific radioactivities of bound sialic acid from sialoglycoproteins of rat liver and of serum after a single injection of $100 \mu \mathrm{Ci}$ of $\left.{ }^{3} \mathrm{H}\right] \mathrm{ManNAC}$

Starved rats: $\mathbf{O}$, liver; 0 , serum. Normal rats: $\Delta$, liver; $\Delta$, serum. Sp. radioactivity of the injected [ $\left.{ }^{3} \mathrm{H}\right] \mathrm{ManNAc}$ was $19000 \mathrm{Ci} / \mathrm{mol}$.
Lennarz (1981) or via the cytosol. Experiments with isolated Golgi vesicles give support to the latter possibility (Carey et al., 1980; Carey \& Hirschberg, 1981). This transport of CMP-NeuAc from the place of synthesis to the place of incoprporation seems to occur promptly. Approx. $1 \mathrm{~min}$ after the appearance of radioactivity in CMP-NeuAc, incorporation into bound NeuAc of the liver could be detected (Fig. 2). Some difference was found between normal and starved rats, but it is questionable whether this difference is significant. Between 9 and $10 \mathrm{~min}$ after injection, radioactivity began to appear in the circulating sialoglycoproteins. So the transport of sialoglycoproteins from the point of attachment of the sialic acid molecules to the point of excretion took 7-8 min. In this respect the livers of starved rats behaved the same as normal rats. With radioactive glucosamine as precursor an incorporation plus excretion time of approx. $15 \mathrm{~min}$ and $25 \mathrm{~min}$ has been reported for $\alpha_{1}$-acid glycoprotein and transferrin respectively (Schreiber et al., 1979). However, glucosamine serves as a precursor of several sugars and the radioactivity is incorporated at an earlier stage.

We thank Mrs. J. M. Rodenberg for her technical assistance.

\section{References}

Bates, C. J., Adams, W. R. \& Handschumacher, R. E. (1966) J. Biol. Chem. 241, 1705-1712

Beau, J.-M., Schauer, R. \& Haverkamp, J. (1978) Abstr. VIII, Journées sur la Chimie et de la Biochimie des Glucides, Camerolles près d'Orleans

Bergh, M. L. E., Koppen, P. L. \& Van den Eijnden, D. H. (1981) Carbohydr. Res. 94, 225-229

Buscher, H.-P., Casals-Stenzel, J., Schauer, R. \& Mestres-Ventura, P. (1977) Eur. J. Biochem. 77, 297-310

Carey, D. J. \& Hirschberg, C. B. (1981) J. Biol. Chem. 256, 989-993

Carey, D. J., Sommers, L. W. \& Hirschberg, C. B. (1980) Cell 19, 597-605

Coates, S. W., Gurney, T., Sommers, L. W., Yeh, M. \& Hirschberg, C. B. (1980) J. Biol. Chem. 255, 92259229

Corfield, A. P., Ferreira do Amaral, C., Wember, M. \& Schauer, R. (1976) Eur.J. Biochem. 68, 597-610

Ferwerda, W., Blok, C. M. \& Heijlman, J. (1981a) J. Neurochem. 36, 1492-1499

Ferwerda, W., Blok, C. M. \& Van Rinsum, J. (1981b) Proceedings of the VIth International Symposium on Glycoconjugates, Tokyo (Yamakawa, T., Osawa, T. \& Handa, S., eds.), pp. 230-231, Japan Scientific Societies Press, Tokyo

Gielen, W., Schaper, R.\& Pink, H. (1970) Hoppe-Seyler's Z. Physiol. Chem. 351, 768-770

Gielen, W., Schaper, R.\& Pink, H. (1971) Hoppe-Seyler's Z. Physiol. Chem. 352, 1291-1296 
Hanover, J. A. \& Lennarz, W. J. (1981) Arch. Biochem. Biophys. 211, 1-19

Harms, E. \& Reutter, W. (1974) Cancer Res. 34, 3165-3172

Harms, E., Kreisel, W., Morris, H. P. \& Reutter, W. (1973) Eur. J. Biochem. 32, 254-275

Irwin, L. N., Mancini, J. \& Hills, D. (1973) Brain Res. 53, 488-491

Jourdian, G. W., Swanson, A. L., Watson, D. \& Roseman, S. (1964) J. Biol. Chem. 239, 2714-2716

Kean, E. L. (1970) J. Biol. Chem. 245, 2301-2308

Kean, E. L. \& Bighouse, K. J. (1974) J. Biol. Chem. 249, 7813-7823

Masters, C. J. (1978) Trends Biochem. Sci. 3, 206-208

McGuire, E. J. (1976) in Biological Roles of Sialic Acid (Rosenberg, A. \& Schengrund, C.-L., eds.), pp. 123158 , Plenum Press, New York

Molnar, J., Robinson, G. B. \& Winzler, R. J. (1964) J. Biol. Chem. 239, 3157-3162

Schachter, H. (1974) Biochem. Soc. Symp. 40, 57-71

Schachter, H. \& Roseman, S. (1980) in The Biochemistry of Glycoproteins and Proteoglycans (Lennarz, W. J., ed.), pp. 85-160, Plenum Press, New York and London

Schreiber, G., Dyrburgh, H., Millership, A., Matsuda, Y.,
Inglis, A., Philips, J., Edwards, K. \& Maggs, J. (1979) J. Biol. Chem. 254, 12013-12029

Summerfield, J. A. (1982) Falk Symp.: Structural Carbohydrates in the Liver 34, 60 (abstr.)

Van den Eijnden, D. H. (1973) J. Neurochem. 21, 949-958

Van Dijk, W., Ferwerda, W. \& Van den Eijnden, D. H. (1973) Biochim. Biophys. Acta 315, 162-175

Van Dijk, W., Maier, H. \& Van den Eijnden, D. H. (1976) Biochim. Biophys. Acta 444, 816-834

Van Dijk, W. Maier, H. \& Van den Eijnden, D. H. (1977) Biochim. Biophys. Acta 466, 187-197

Van Rinsum, J., Van Dijk, W., Hooghwinkel, G. J. M. \& Ferwerda, W. (1983) Biochem. J. 210, 21-28

Voisey, J. R. \& Winterburn, P. J. (1982) Biochem. Soc. Trans. 10, 275-276

Warren, L. (1959) J. Biol. Chem. 234, 1971-1975

Warren, L. (1972) in Glycoproteins (Gottschalk, A., ed.), pp. 1097-1126, Elsevier Publishing Co., Amsterdam, London and New York

Warren, L. \& Felsenfeld, H. (1962) J. Biol. Chem. 237, 1421-1431

Watson, D. R., Jourdian, G. W. \& Roseman, S. (1966) J. Biol. Chem. 214, 5627-5636 